\title{
Pressões e Protagonismos na Trajetória de Trabalhadores de Marechal Cândido Rondon - Paraná (2000-2016)*
}

\author{
Presiones y Protagonismos en la Trayectoria de Trabajadores de \\ Marechal Cândido Rondon - Paraná (2000-2016) \\ Pressures and Protagonisms in the Trajectory of Workers of Marechal \\ Cândido Rondon - Paraná (2000-2016)
}

Saionara Lagos ${ }^{1}$

\begin{abstract}
Resumo
Essa proposta trata da investigação e problematização sobre os possíveis sentidos expressos na disposição de trabalhadores ao se colocarem a procura de trabalho, propondo uma reflexão sobre as possibilidades de trabalho na cidade de Marechal Cândido Rondon entre os anos de 2000-2016, e de que forma estas relações modificam os modos de viver e produzir a cidade. Para tal propósito, tratamos as fontes de modo a considerá-las construções pautadas em interesses, o que não minimiza sua riqueza, mas instiga a problematizar como em um mesmo momento histórico as preocupações expressas podem ser divergentes ou mesmo contraditórias. A investigação foi construída através da análise de fontes como entrevistas com trabalhadores, o jornal local "O Presente" no qual pesquisamos matérias que tratam da presença destes trabalhadores na cidade, neste mesmo jornal analiso os anúncios de procura por trabalho em uma tentativa de acessar o modo como estes sujeitos têm se colocado nestas relações e fichas de cadastro de trabalhadores no SINE (Sistema Nacional de Emprego), a partir delas é possível perceber os trabalhadores se articulando frente ao seu objetivo de conquistar uma vaga e aquilo que acreditam ser positivo frente aos contratantes, e também um pouco sobre suas relações de trabalho, mesmo que não em sua totalidade. Analisar a atuação de trabalhadores nos últimos anos nos permite perceber espaços de confrontação nos quais estes sujeitos decidem como e onde trabalhar a partir do modo como vivem ou almejam viver.
\end{abstract}

Palavras-chave: Relações, Trabalho, Trabalhadores.

\section{Resumen}

Esta propuesta trata de la investigación y problematización sobre los posibles sentidos expresados en la disposición de los trabajadores al plantearse la demanda de trabajo, proponiendo una reflexión sobre las posibilidades de trabajo en la ciudad de Marechal Cândido Rondon entre los años 2000-2016, y de qué forma Estas relaciones modifican los modos de vivir y producir la ciudad. A tal propósito, tratamos a las fuentes para considerarlas construcciones pautadas en intereses, lo que no minimiza su riqueza, pero instiga a problematizar como en un mismo momento histórico las preocupaciones expresas pueden ser divergentes o incluso contradictorias. La investigación fue construida a través del análisis de fuentes como entrevistas con trabajadores, el periódico local "O Presente" en el que investigamos materias que tratan de la presencia de estos trabajadores en la ciudad, en este mismo periódico analizamos los anuncios de búsqueda por trabajo en un intento de acceder al trabajo Como estos sujetos se han colocado en estas relaciones y fichas de registro de

\footnotetext{
* Trabalho apresentado no I Seminário Latino-Americano de Estudos em Cultura -SEMLACult, Foz do Iguaçu/PR, Brasil, 2017. Esta proposta é parte de reflexões que compõe o trabalho de produção de dissertação para programa de pós-graduação em História pela Universidade Estadual do Oeste do Paraná.

${ }^{1}$ Graduada em História pela Universidade Estadual do Oeste do Paraná (2014). Mestranda no Programa de Pósgraduação em História - Área de concentração: História, poder e práticas sociais, Linha de pesquisa: Trabalho e movimentos sociais, pela Universidade Estadual do Oeste do Paraná. Marechal Cândido Rondon, Paraná, Brasil. saionaralagos@hotmail.com.
} 
trabajadores en el SINE (Sistema Nacional de Empleo), a partir de ellas es posible percibir a los trabajadores articulándose frente a su objetivo de conquistar una plaza y aquello que creen ser positivo frente a los que creen Contratistas, y también un poco sobre sus relaciones de trabajo, aunque no en su totalidad. Analizar la actuación de los trabajadores en los últimos años nos permite percibir espacios de confrontación en los que estos sujetos deciden cómo y dónde trabajar a partir del modo como viven o anhelan vivir.

Palabras clave: Relaciones, Trabajo, Trabajadores.

\begin{abstract}
This proposal deals with the investigation and problematization of the possible meanings expressed in the disposition of workers in the search of work, proposing a reflection on the possibilities of work in the city of Marechal Cândido Rondon between the years of 2000-2016, and how These relations modify the ways of living and producing the city. For this purpose, we treat sources in a way that considers them constructions based on interests, which does not minimize their wealth, but instigates to problematize how in a same historical moment the expressed concerns can be divergent or even contradictory. The investigation was constructed through the analysis of sources such as interviews with workers, the local newspaper "O Presente" in which we researched subjects that deal with the presence of these workers in the city, in the same newspaper, analyze job search advertisements in an attempt to access the In this way, as these subjects have been placed in these relations and records of workers registration in the SINE (National System of Employment), from these it is possible to perceive the workers if articulating in front of their objective to conquer a vacancy and what they believe to be positive vis- Contractors, and also a little about their working relationships, even if not in their entirety. Analyzing the work of workers in recent years allows us to perceive spaces of confrontation in which these subjects decide how and where to work from the way they live or aim to live.
\end{abstract}

Keywords: Relationships, Work, Workers.

\title{
1. Avaliações por onde e como trabalhar: limites e confrontações
}

"Passa o dia, acabo o dia, eu mesma, eu to prevendo pra trabalha de noite, pra manter trabalha de dia e de noite, sempre fiz isso trabalha de dia e de noite"

A necessidade de trabalhar durante o dia e a noite merece no mínimo um estranhamento, estranhamento manifestado também por Paulo que ao nos contar sobre o quanto trabalhava aos 15 anos (ao ser questionado sobre como fazia para estudar), constrói a

\footnotetext{
${ }^{2}$ FÁTIMA (pseudônimo). Entrevista realizada por Saionara Lagos, no Centro de Referência de Assistência Social (CRAS), no dia 11/06/2014. Marechal Cândido Rondon-PR. Agradeço aos responsáveis pelo órgão por indicarem trabalhadores cadastrados para que eu pudesse realizar entrevistas e permitirem a realização das mesmas no CRAS. Os nomes dados aos entrevistados são pseudônimos, pois apesar destes terem concordado com a gravação da entrevista, consideramos prudente manter o sigilo sobre sua identificação.
} 
seguinte narrativa: "Estudava, é mesmo cara, eu estudava!! Eu trabalhava o dia inteiro!! É, eu estudava no Eron Domingues". 3

Ele se mostra desconcertado frente à quantidade de trabalho que realizava enumerando carga horária de trabalho, o serviço pesado em uma fábrica de tanques de concreto, a correria entre o trabalho e a escola, e desta para a Academia onde realizava treinos de luta, retornando de madrugada para casa. Mas, quase ao fim da entrevista retoma essa questão e recoloca a razão para tal empenho; com o pai alcoólatra, ele tinha que "trazer comida para casa".

Uma condição que escancara a desigualdade, indícios da exploração exacerbada, mas para além do quão desumana me parecem essas relações; como Paulo, Fátima e outros trabalhadores têm tratado essa condição? Uma pergunta que tem me acompanhado há bastante tempo, mais especificamente, desde que passei a ter uma rotina de trabalho muito parecida com a deles.

Decidi começar o texto com aquele trecho da fala de Fátima, que foi também o início da nossa entrevista, porque ela tratava explicitamente da questão da minha problemática, da qual me aproximei ao perceber os sentidos do trabalho na minha experiência e de trabalhadores com os quais eu convivia em Marechal Cândido Rondon- $\mathrm{PR}^{4}$, e que foram fundamentais na formulação de meu interesse em entender como se davam as relações e possibilidades de trabalho (no séc. XXI) em Marechal e de que forma elas modificam os modos de viver e produzir a cidade.

Alguns dos incômodos que essas trajetórias despertavam era a constante movimentação desses trabalhadores, seja na procura por novos postos de trabalho, mudança de uma relação de trabalho para outra seja no acúmulo de diferentes atividades. Na medida em que analiso a dinâmica da experiência de trabalhadores que assim como Fátima e Paulo expressam suas labutas, coloco-me a pensar no trabalho de Santos (2016), que no início de sua tese, a qual trata da movimentação social de trabalhadores, também na cidade de Marechal, na segunda metade do século XX, se propõe a:

Reconhecer que as presenças destacadas visualizam ações/avaliações de homens e mulheres que chegaram, partiram e/ou retornaram de diversos lugares.

Ao fazer isso proponho argumentar que suas presenças são as afirmações positivas de seus interesses e valores, assumindo que suas movimentações são mais do que

\footnotetext{
${ }^{3}$ PAULO (pseudônimo). Entrevista realizada por Saionara Lagos e Sheille S. Freitas, na residência do entrevistado, no dia 21/12/2012. Marechal Cândido Rondon-PR.

${ }^{4}$ Ao longo do texto utilizarei como referência ao nome da cidade apenas Marechal.
} 
deslocamentos, que suas ações expressam os modos de vida e de luta estabelecidos por um conjunto significativo de trabalhadores. Isto posto, defendo a tese de que essa disposição interpretativa abre a possibilidade de sair do marco emoldurado em que foi colocada a noção de "movimento social", passando à dinâmica da "movimentação social de trabalhadores" (IBIDEM, p.17)

Esta é uma proposição que tem acompanhado minha reflexão sobre a atuação de trabalhadores no processo histórico e o modo como pretendo abordá-los. Provocações, nesse sentido, foram tomando forma ao tratar as fontes, dentre elas, destaco a entrevista com Fátima. Ela foi significativa para essa discussão, foi representativa desses sujeitos que a todo momento avaliam ações a partir da dinâmica entre seus "interesses e valores" e as condições de classe que enfrentam; ações marcadas pela desigualdade e capazes de expressar a dificuldade e os limites de suas escolhas, assim como as ações que estava planejando realizar quando conversamos:

\begin{abstract}
Saionara: e assim você ta satisfeita agora com teu trabalho ou você ainda pensa em tenta uma outra coisa, de repente... uma hora, que nem você falou que você pretende futuramente ter mais túmulos lá pra cuidar e ficar só lá[na zeladoria de túmulos] né? Fátima: Só lá, mas, antes disso, eu só to esperando a casa Gaza pra volta, pra entra ali, pra trabalha ali, não sei... eu falo assim, que eu vou entra e vou fica pouco tempo, agora pode ser que eu fico né? mas porque o meu medo é esse, depois que eu entro, eu não saio mais, e eu falo pra ele, eu falei pra ele "eu vou entra trabalha pra você, só que eu vou fica até eu ter uma quantidade de túmulo lá assim pra mim", mas eu já to assim pensando e somando sabe, se eu pegar uns quatrocentos, por ai, eu consigo joga assim todos os dias de manhã cedo, nem que eu vou no fim de semana também, pra daí sobra a tarde pra mim trabalha lá, e daí como eu vou trabalhar lá de quarta a sábado, vai sobra o domingo, a segunda e a terça pra minha casa, e daí na parte da tarde eu faço isso na minha casa né? E a manhã, de manhã cedo, eu vou lá pro cemitério.

To me planejando já, sim, daí aonde que eu vou ta organizada, minha casa e dois emprego, de dia e de noite (risos). Só to pensando que daí, que hora que eu vou ver meu nenê coitadinho, que hora que eu vou ver ele? ${ }^{5}$
\end{abstract}

No momento da entrevista realizava a limpeza de 28 túmulos, pretendia aumentar muito esse número para que o trabalho pudesse proporcionar uma renda satisfatória a seus interesses, planejava conciliar os trabalhos que realizava como zeladora de cemitério aos demais - faxinas em obras e cozinheira em restaurante (que chamou pelo lugar em que o mesmo se localiza - "Casa Gaza"), no qual começaria a trabalhar assim que a reforma tivesse finalizada. Fátima evidencia toda a dificuldade de sua decisão, não pelo cansaço, o que

\footnotetext{
${ }^{5}$ FÁTIMA (pseudônimo). Entrevista realizada por Saionara Lagos, no Centro de Referência de Assistência Social (CRAS), no dia 11/06/2014. Marechal Cândido Rondon-PR.
} 
provavelmente reconhece e faz parte de sua rotina de trabalho, mas pela preocupação com o tempo, ou a falta dele ao não conseguir estar presente nos cuidados com o filho menor.

A pergunta com que finaliza sua frase escancara a dureza da necessidade, da dificuldade de conciliar uma prática de trabalho exaustiva e sua presença na rotina do filho mais novo, o qual conta com os cuidados da creche e a ajuda da filha de quinze anos. Além disso, ainda tem sua mãe acamada para revezar com a filha nos cuidados.

Mesmo que aponte essa condição como extrema e, portanto, que deveria ser mantida apenas de forma temporária, não sabe se não dará continuidade aos turnos excessivos. Sua trajetória é marcada pelo que denominou como "sempre fiz isso, trabalha de dia e de noite"6. Com isso, revela a dificuldade de romper com estas relações frente ao conjunto de urgências expressas na sua condição de trabalhadora.

O que constrói durante a nossa conversa enquanto planos não é necessariamente trabalhar menos, mas ter uma quantidade ainda maior de túmulos para limpar, pois mais do que os 400 que indicou primeiro, para poder trabalhar apenas no cemitério e poder organizar melhor seus horários, o que pesa para ela é que essas decisões são compostas por resolver, também, os cuidados com a família, com a sua casa.

Toda a dinâmica envolvida nas relações vivenciadas por Fátima nesse campo de pressões, revela a complexidade destas relações, o que me leva a acreditar na relevância de discussões acerca das tensões dessa movimentação social e do significado delas para a experiência desses trabalhadores na contemporaneidade.

Nesse sentido o objetivo tem sido compreender o que os trabalhadores buscam e confrontam em suas investidas de trabalho, indicar que essa é uma condição precária não traduz os sentidos que os trabalhadores atribuem a tais ações e decisões (por acúmulos de atividades ou mesmo de ampliar campos de trabalho e renda) é preciso identificar o que os motiva, como avaliam essas decisões de trabalho e como organizam suas vidas em função de horários, tarefas e ganhos, que pressões e expectativas enfrentam e o que os fazem lidar com esses trabalhos, ainda que reconheçam o desequilíbrio do campo de forças em que se veem inseridos.

São estes incômodos que me fazem aproximar da experiência desses trabalhadores, penso estas questões à luz das reflexões de Thompson (1988). O autor ao tratar das relações de trabalho no contexto da revolução industrial lidou com determinada historiografia e diante

\footnotetext{
${ }^{6}$ FÁTIMA (pseudônimo). Entrevista realizada por Saionara Lagos, no Centro de Referência de Assistência Social (CRAS), no dia 11/06/2014. Marechal Cândido Rondon-PR.
} 
dela se colocou a perceber a experiência da exploração frente à intensificação das relações de trabalho naquele período, ou seja, como as mudanças nas relações foram percebidas pelos trabalhadores e por aqueles que compunham aquela sociedade. Sua análise me sugere que só ao tratar das pessoas avaliando e agindo é que acessamos a experiência e sua consciência. Os sujeitos vivenciando, observando e tratando daquela realidade traduzem a experiência social.

Thompson trata do conceito exploração e da sua intensificação na sociedade industrial, mas de forma não estática. Ao estar presente em toda sua discussão, esse debate se faz não pelo termo, mas ao pensar como "relação de exploração", ou seja, a vida de trabalhadores não como reflexo das mudanças estruturais, mas a experiência de relações de exploração.

Ao discutir algumas questões teóricas acerca da ampliação dos métodos e fontes históricas no texto "Folclore, Antropologia e História Social" no debate com a tradição marxista, Thompson (2001) traz suas proposições acerca desse modo de investigar os trabalhadores e reconhecer suas lutas nas próprias relações e pelo seu modo de viver: "A transformação da vida material determina as condições dessa luta e parte de seu caráter, mas o resultado especifico é determinado apenas pela luta em si mesma” (IBIDEM, 2001, p. 263)

Uma análise a partir destas proposições exige que a dinâmica do processo seja assumida, desta forma afastei-me de noções como "fluxos econômicos" e "reestruturação produtiva", e privilegiei compreender a condição de classe que possuem como terreno comum na cidade e, ao mesmo tempo, a diversidade de sentidos que atribuem às desigualdades, urgências e expectativas que formulam e vivenciam enquanto pressão e limite de suas práticas e possibilidades de trabalho.

Esse procedimento permitiu associar valores e limites para decidir por certas atividades, as relações de trabalho mantidas por Paulo aos 15 anos têm relação direta com o modo como vivia sua família, a condição dos pais e sua responsabilidade em "trazer comida para casa"7. Não podemos entender o modo como experienciou essas relações se não estiverem em seu contexto, não o contexto enquanto algo estático, mas um processo, o qual não está isolado do que aconteceu no momento em que vivia. (THOMPSON, 2001). Sendo assim, o que significava para Paulo experimentar essas relações na década de 1990 em Marechal? Como avalia, mais de uma década depois dessa experiência juvenil, possuir, na atualidade, várias relações de trabalho para contingenciar gastos e construir alternativas na cidade?

\footnotetext{
${ }^{7}$ PAULO (pseudônimo). Entrevista realizada por Saionara Lagos e Sheille S. Freitas, na residência do entrevistado, no dia 21/12/2012. Marechal Cândido Rondon-PR.
} 
As mudanças e vínculos em determinadas relações de trabalho têm de ser pensadas como ações que envolvem todo o modo de viver dos sujeitos, pois elas estão intrinsecamente ligadas às suas decisões sobre como irão viver e como vão lidar com determinadas pressões e valores. Portanto é preciso analisar elos e pontos divergentes, pois esses são elementos que tornam mais densa a reflexão sobre as relações e práticas de trabalhadores na sociedade.

O que determina a condição de classe destes trabalhadores, passar por esse terreno comum do qual falei, não me parece ser a categoria em que trabalham, mas o sentimento de exploração, ponderam questões diferentes, lidam de formas distintas com suas trajetórias e atividades e, por isso, um aceita fazer determinada atividade e outro não, o que não reduz a aproximação que produzem frente à condição de classe, pois compartilham restrições, práticas e valores, por mais que isso não signifique unidade esquemática de costumes e alternativas.

Dessa forma, tenho procurado entender os entraves e interesses que permeiam os posicionamentos de trabalhadores na concorrência ou solidariedade frente à certas relações de poder, a fim de entender o social como um lugar de tensões e de experiências contraditórias, e não como um campo definido por determinações econômicas no seu sentido mais estrito.

Iniciei a produção de entrevistas com o interesse de entender a maneira como os trabalhadores têm organizado suas rotinas e relações de trabalho a partir de interesses e pressões para se ocupar, procurei perceber os sujeitos interpretando suas trajetórias, as relações por eles vivenciadas, acredito que "Buscamos fontes orais porque queremos que essas vozes - que, sim, existem, porém ninguém as escuta, ou poucos as escutam - tenham acesso à esfera pública, ao discurso público, e o modifiquem radicalmente"(PORTELLI, 2010, p. 2).

Esta é uma importante característica do nosso trabalho, ouvir esses trabalhadores, nessa medida tenho procurado não apenas ouvir, mas dar espaço em meu trabalho para as ações e avaliações dos trabalhadores ganharem força. Essa não é uma possibilidade apenas quando tratamos de entrevistas, todas as minhas fontes podem evidenciar uma memória construída por ou sobre trabalhadores, mesmo que produzidas com finalidades outras.

As questões já apontadas foram sendo vinculadas às demais fontes, como as outras entrevistas; além do jornal "O Presente" - no qual pesquisei matérias que tratam da presença desses trabalhadores na cidade. Nele observo o uso de parte de seu espaço na tentativa de construir certa interpretação quanto à movimentação social de trabalhadores; neste mesmo jornal analiso os anúncios de procura por trabalho em uma tentativa de acessar o modo como esses sujeitos têm se colocado nessas relações. 
Além desses materiais, utilizo as Fichas de cadastro de trabalhadores no SINE (Sistema Nacional de Emprego). Procurei a agência do SINE de Marechal com o objetivo de perceber como se dava o processo de procura dos trabalhadores por ela enquanto intermediária entre eles e os empregadores, interessava, inclusive, observar os encaminhamentos para as empresas que realizavam.

Acredito ser importante dar espaço aqui para falar sobre minha dificuldade em tratar das fichas na construção do texto. Passado o primeiro momento de êxtase por conquista-las, resisti muito em trabalhar com elas, entendia que eu não precisava e não era meu objetivo fazer análise do SINE, mas discutir sobre a presença dos trabalhadores no SINE e naquelas relações, isto é, os usos que faziam da agência enquanto intermediária e o que aquela fonte trazia para além do evidente cadastrado de trabalho.

Talvez, assim como Thompson ao tratar do Folclore (2001), eu possa inicialmente ter desconsiderado todo o potencial deste material e o que eu poderia fazer com ele - o modo como o autor trata de seu posicionamento e da necessidade de expandirmos as fontes históricas me fez repensar o que eu queria com as fichas, eu precisava entender que elas não eram meu objeto, e que o meu procedimento é que tiraria delas evidências significativas para a produção do trabalho. Essa ação poderia alterar a condição inicial das Fichas de serem mais que índices, pois poderiam me mostrar a movimentação por vagas, visualização destas vagas e das circunstâncias do trabalho, como esses trabalhadores se davam a conhecer quando iam procurar uma vaga no SINE (idade, escolarização, renda, atividades, períodos de contratos...)

As fichas são limitadas, contraditórias e imperfeitas, não podem me dar respostas fáceis, e isso torna o trabalho bastante árduo e ingrato de certa forma, mas e se lançasse um olhar diferente a elas? Eu quero fontes perfeitas ou indícios necessários? E se eu não estivesse à procura de um ponto final. Fontes não são o que foi o momento, mas indícios sobre ele.

Minhas outras evidências também não são completas, preciso lidar com as lacunas e contradições de todas elas, todas deixam dúvidas, a questão é como posso resolver? E se eu tentasse relacioná-las a seu contexto por meio de outras fontes ou com a historiografia? $\mathrm{O}$ modo como tenho tentado lidar com minhas fontes é me afastar de uma descrição, preciso percebê-las enquanto documento provocador de reflexões sobre aquele tempo e aqueles sujeitos. Um registro construído a partir de determinadas relações e entender essa teia de relações pode ser a chave para lidar com as fichas e demais entraves do processo de investigação.

O contanto com esse conjunto de fontes, relacionado a outros incômodos, possibilitaram a construção dos questionamentos que movem minha problemática de 
pesquisa: como ocorre a busca por trabalho na cidade? O que os trabalhadores levam em consideração na hora de se propor a ocupar determinadas vagas e outras não? Quais as vagas que estão sendo recusadas? Como lidam com os momentos de desemprego? Onde e quando procurar? Inscrevendo-se no SINE? Através de um anúncio no jornal? Como criam estratégias, quando decidem por permanecer na vaga conquistada e como procuram se destacar entre os candidatos a uma vaga de trabalho? E talvez, ainda, o mais significativo, quais os sentidos do trabalho que expressam? Como avaliam e significam as relações vivenciadas na cidade? Como vivenciam e disputam a cidade? Neste trabalho a intensão é tratar de algumas destas interrogações.

Motivados por questões que, de modo mais específico, variam, mas que se percebidos frente às relações sociais apontam para pressões e incômodos compartilhados (quanto às condições com que trabalham e vivem), avalio que trabalhadores olham socialmente e percebem o quão desigual são suas condições de classe, e passam a movimentar-se de um trabalho para outro, de uma região para outra em grande parte mobilizados em alterar tais circunstâncias. Uma movimentação pressionada e limitada destes sujeitos que parece ser fruto de uma busca por alternativas, uma ação mesmo que restrita e desigual.

Percebo que para muitos trabalhadores as relações de trabalho são uma verdadeira corrida contra o tempo procurando transformar melhores salários em certas condições mais favoráveis (para morar, alimentar, cuidar da saúde etc.). Entre trabalhar e manter os cuidados com a casa, ter algum trabalho com jornada regular diária e ainda realizar outros trabalhos para garantir um extra na renda da família observamos que essa junção de práticas não são exceções no campo de possibilidades de trabalhadores.

Afinal, essa prática de exploração do trabalho (que expõe certas fragilidades experimentadas socialmente) sugere que mudanças de um trabalho para outro, quando vislumbradas, não são apenas por melhores condições de trabalho, podem ser positivadas por diversas razões, e em um primeiro momento (salário, horários mais flexíveis, atividade a ser realizada e sua visibilidade social podem ser vistas como um rearranjo na desigualdade) o que às vezes requer toda uma mudança na organização e cotidiano da família, ou seja, na maioria dos casos os trabalhadores não estão satisfeitos e estáveis no trabalho em que se encontram e nem mesmo no que se vinculam, apenas procuram ou conciliam atividades até que possam decidir em quais vagas permanecer, ainda que não considere nenhuma delas sem ambiguidades e prejuízos ao seu modo de vida.

No momento da entrevista, Fátima possuía 41 anos e morava em uma casa alugada com seus dois filhos mais novos (um menino de um ano e oito meses e uma menina de 15 
anos), sendo que seu filho mais velho possui 26 anos e já é casado. Sua mãe também reside com eles, a qual precisa de cuidados, pois sofreu um derrame e tem dificuldade para realizar movimentos. Em um dos momentos de nossa conversa ela justifica as relações de trabalho que vivencia e sua necessidade de trabalhar "de dia e de noite", construindo a seguinte formulação:

Fátima: só que daí... tipo, digamos que eu to ganhando um salário ( $\mathrm{R} \$ 724,00)$, o que que eu vou fazer? Eu tenho duas criança em casa, digamos... a situação que o meu marido não pode me ajudar ${ }^{8}$, eu vou alugar uma casa, que nem a que eu tenho lá, a casa que eu aluguei, é $\mathrm{R} \$ 550,00$ o aluguel da casa, mais a luz, mais a água, então você vai viver só pra pagar o aluguel, a luz e a água? Você não tem direito de comer? Ah, sobrou pra comida, você pode comer, mas daí você não tem direito de vestir? Você não tem direito de ficar doente?! Porque você não vai ter dinheiro pra compra um remédio 9 .

Quais as condições de vida que estavam sendo recusadas por Fátima ao não aceitar a renda que apenas um destes vínculos poderia lhe proporcionar? E quais alterações ou necessidades seriam respondidas ao decidir por este caminho? Seu planejamento demonstra que ela talvez tenha feito essas mesmas perguntas. Pois, decidir por enfrentar sua condição de classe dessa maneira exigiu dela uma avaliação, a qual não se pretende definitiva, mas de acordo com as condições e possibilidades que se apresentavam naquele momento e reconhecendo o campo de forças social do qual faz parte.

Sua explicação a partir da dificuldade em manter as despesas da casa com o salário que um determinado campo de trabalho poderia lhe proporcionar, indica como avalia a remuneração das vagas de trabalho disponíveis à grande maioria dos trabalhadores da cidade na mesma condição que a sua, que são em grande parte o salário mínimo (ou pouco mais que isso). Ao usar esse valor como base para seu cálculo, Fátima acredita que esse problema é compartilhado e como é reconhecido como um pagamento incondizente com a realidade (de trabalho realizado e necessidade), uma vez que conforme argumente não é capaz de responder nem mesmo às necessidades básicas de uma família, portanto ainda mais distante de poder responder outras expectativas que podem perpassar alterações na sua condição de classe.

Tudo isso, precisa ser mediado pelo lugar onde encontrei Fátima, estávamos no CRAS, um local em que esses trabalhadores expõem esses limites e confrontam seus valores e

\footnotetext{
${ }^{8}$ Está separada e seu ex-marido não paga pensão para os dois filhos, mas disse que ele a ajuda pagando, por exemplo, sua conta na farmácia.

${ }^{9}$ FÁTIMA (pseudônimo). Entrevista realizada por Saionara Lagos, no Centro de Referência de Assistência Social (CRAS), no dia 11/06/2014. Marechal Cândido Rondon-PR.
} 
direitos para recompor sua permanência na cidade. Falar dessa condição e indicar o porquê muitos trabalhadores que trabalham ainda assim não conseguem subsistir parecia uma questão fundamental para ela.

Sua fala provoca questionamentos sobre que relações de trabalho são essas que não são capazes de garantir para muitos trabalhadores moradia, alimento e vestuário de uma só vez? Como agir diante da necessidade de escolher entre o que garantir quando não se tem acesso a tudo e na mesma qualidade que outros, experimentando a desigualdade? Sua indignação aponta que nessas condições uns não têm, mas outros não enfrentam essa dificuldade.

O adoecimento de alguém da família seria um gasto imprevisto e ao mesmo tempo inevitável, e que, em alguns casos, pode afetar sua relação de trabalho e demais aspectos de seu modo de vida, como lidam com essas situações? Como a experiência da exploração influencia em decisões de trabalhadores como Fátima?

Sua construção narrativa se dá em tom de indignação, reforçado pelo modo como enfatiza que tem "direitos" e faz parte desta sociedade. Essa força em sua fala está presente em toda a entrevista e esgarça o sentimento de exploração, contraposto por limites e entraves que recolocam sua disposição em lidar com esses enfrentamentos. Esse sentimento de exacerbação nessas relações, expresso, inclusive, na materialidade do que significa o achatamento dos salários apareceu com força em todo o desenvolvimento da pesquisa na conversa com os trabalhadores.

Esse sentimento de exacerbação nessas relações apareceu com força também na fala de Paulo, ao perguntarmos sobre o que o motivava conciliar diferentes ocupações, ele que argumentou que:

Paulo: Ah os bens né? Bens materiais primeiro, né? Porque acho que só o salário do dia a dia da gente é complicado. Se for analisá bem aí o salário de Rondon é até vergonhoso se for olhar no geral, porque depende... o funcionário aí milão, dá mil e pouquinho né cara? Mas o cara que trabalha na Copagril aí dez horas por dia pra ganhá 720 pila e uma cesta básica, da onde que o cara vai conseguir sobreviver com só isso daí? É o mínimo, pagá aluguel, luz e água, da onde ${ }^{10}$

No momento da entrevista Paulo tinha 35 anos, trabalhava durante o dia em horário comercial em uma empresa, como garçom em uma pizzaria nas noites de sexta, sábado e

\footnotetext{
${ }^{10}$ PAULO (pseudônimo). Entrevista realizada por Saionara Lagos e Sheille S. Freitas, na residência do entrevistado, no dia 21/12/2012. Marechal Cândido Rondon-PR.
} 
domingo, nas noites de segunda e quarta ele é professor/instrutor de luta em uma academia (quando não tem essa atividade, trabalha na pizzaria nesses dias). Além disso, nos sábados e domingos ao meio dia ele trabalha como garçom em um restaurante. Mora na casa de sua mãe, vivendo só os dois na residência e, no momento, não estava casado.

Ao expressar suas motivações, assim como Fátima, Paulo interpreta a situação dos salários oferecidos na cidade, tratando da condição de um conjunto de trabalhadores, e sua indignação quanto à remuneração destes, que em situações ainda mais desfavoráveis, recebem "720 pila" mensais ${ }^{11}$. Sua visão é de que o salário oferecido pela grande maioria das vagas na cidade, como a indicada em sua fala, que são em grande parte em linhas de produção das principais empresas de alimentos instaladas na cidade. Essas vagas são visualizadas por Paulo enquanto possibilidades de trabalho com remuneração vergonhosa e isso o levou a avaliar outros caminhos.

Sua busca por responder às expectativas que construiu, que justificou como "bens materiais", traz o que no primeiro momento de uma conversa é difícil para ambos construir: a aproximação para indicar as fragilidades da trajetória e das decisões necessárias a serem tomadas. Obviamente, não aceitar a desigualdade imposta pode ser uma leitura mais importante a ser feita do que simplesmente apontar um interesse pelo consumo. Afinal, o que Paulo aspirava? A aquisição de uma casa própria em um conjunto habitacional? Um automóvel em uma cidade sem transporte público? Refazer-se após uma separação? Não acredito que esses bens materiais traduzam apenas o vínculo a essas relações de trabalho pelo interesse em consumir. A complexidade de sua vida aponta outras nuances a observar. $\mathrm{O}$ desejo de sentir-se reconhecido pelo que faz e pelo modo como pretende se situar socialmente nesse novo momento de sua vida, legitimam, em grande parte, as relações que tem vivenciado e sua corrida por tantos postos de trabalho.

A mudança contínua de trabalho assim como o acúmulo de atividades, aparecem na experiência desses sujeitos como um não contentamento em viver dentro de determinadas condições que as relações de trabalho predominantes podem proporcionar, pois visualizam em suas ações uma possibilidade de alteração no seu modo de viver. Elas explicitam não só uma busca por corresponder necessidades de sobrevivência, apesar de estarem em primeiro plano, mas há, também, expectativas com as quais estão lidando, com planejamento de vida que vêm construindo.

\footnotetext{
${ }^{11}$ No início de 2012 (antes do reajuste) o valor do salário mínimo do Paraná era de R\$ 783,20 e o piso nacional era $\mathrm{R} \$ 678,00$.
} 
Mesmo que com motivações e pressões diferentes para manter as relações de trabalho as quais se vinculavam, chama atenção que nos trechos das narrativas de Paulo e Fátima, eles escolheram destacar mais a certeza das condições que estão procurando fugir do que aquilo que têm ou pretendem ter, o que parece indicar que, apesar de construírem expectativas, sabem que as alterações ou melhorias no modo de vida não são garantidas apenas por prospecções e escolhem construir suas justificativas ou interpretações a partir daquilo que vem sendo negado ao construir esse caminho.

Essa fuga ou rejeição a determinados trabalhos na cidade, seja pela renda ou pelas condições nas quais são exercidos, têm chamado a atenção de outros pesquisadores:

\begin{abstract}
$\mathrm{Na}$ disputa por espaço nos noticiários, a repetida propaganda no implemento da produção industrial compartilhava divulgação com outro tema constante: a indisponibilidade de mão de obra para o setor, notadamente para os frigoríficos. E no que se refere especificamente a estes, os dados do Caged confirmavam a suposta preocupação empresarial: em média, aqueles empreendimentos mantiveram índices de "rotatividade" - termo usado pela classe patronal - de empregados superiores a $55 \%$ entre os anos de 2005 e 2012, chegando a extremos de $110 \%$ em algumas plantas. (VARUSSA, 2016, p. 34)
\end{abstract}

Os índices apontados por Varussa evidenciam o não contentamento dos trabalhadores com essas atividades e a movimentação destes na procura por alterarem de suas relações de trabalho algo que tem estado na pauta do noticiário que, em geral, expressa o posicionamento do empresariado da cidade. Mas essa "indisponibilidade" é um processo complexo, não basta negar essas relações, a necessidade desses sujeitos exige que essas ações sejam acompanhadas por outras saídas, por soluções mesmo que temporárias. Uma das maneiras pelas quais esses direcionamentos se dão é apontado em outro texto de Varussa (2013):

De qualquer forma, o seguro-desemprego parece ter se configurado numa possibilidade com a qual os trabalhadores da região vinham jogando, ao menos na visão do empresariado local que identificava a existência de 'pessoas que para receberem o seguro-desemprego forçam uma demissão’. (IBIDEM, p. 103).

A fala citada pelo autor é a interpretação de um empresário do setor alimentício de Marechal Cândido Rondon, em entrevista ao jornal "O Presente"12, que segue lamentando, pois segundo ele essas ações prejudicam as empresas, sua afirmação minimiza as motivações que levam os trabalhadores a "forçar" uma demissão, de forma a culpabilizar os trabalhadores

\footnotetext{
${ }^{12}$ EMPRESAS enfrentam rotatividade de mão de obra, Jornal O Presente, Marechal Cândido Rondon, 10 março de 2011, p.07.
} 
pelo desenrolar dessas situações, retirando da classe patronal a responsabilidade, ou mesmo, retirando de foco a tensão que perpassa essa relação.

A discussão construída por Varussa trata da forma como se tem feito uso da Justiça do Trabalho nos enfrentamentos entre trabalhadores e empresas do setor de frigoríficos avícolas no Oeste do Paraná, problematizando os sentidos dos autos processuais que em sua maioria terminavam em conciliações e com valores de indenizações baixos frente ao que inicialmente se pleiteava. $\mathrm{O}$ autor mostra que o interesse dos trabalhadores que tomavam essa iniciativa não se restringia ao valor recebido, mas também a outros resultados, sendo um deles a possibilidade de recebimento do seguro desemprego.

O esforço do noticiário em produzir determinada avaliação e o desagrado em suas afirmações sobre essas ações mostram que esse é um campo de disputas, onde a dinâmica da luta de classes, mesmo que por forças desiguais, apresenta a ação desses trabalhadores tentando garantir alguma alteração em suas vidas frente à essa condição vivenciada. Portanto, a dificuldade em contratar trabalhadores é um indício de que não é apenas exploração, mas relação de exploração. (THOMPSON, 1988).

Ao analisar as 31 fichas cedidas e selecionadas pelo diretor da agência do SINE foi possível perceber, a partir delas, os trabalhadores se articulando frente ao seu objetivo de conquistar uma vaga e aquilo que acreditam ser positivo frente aos contratantes e, também, um pouco sobre suas relações de trabalho, mesmo que as fichas não nos permitam conhecêlas em sua totalidade. Nelas, chamou minha atenção que entre as 26 que possuem anexo à ficha os dados do Cadastro Geral de Empregados e Desempregados - CAGED (onde consta os registros em carteira do trabalhador, seu tempo de contrato e também se recebeu algum auxílio previdenciário), 12 desses trabalhadores mantiveram contrato com a empresa Copagril - Unidade Industrial de Aves e desses apenas 3 deles mantiveram-se empregados na empresa por mais de 1 ano, enquanto 7 permaneceram menos de 4 meses.

Penso nesses números não como respostas, mas como problemas, como constroem esse caminho de movimentação? Sabe-se que há resistência por parte da empresa em demitilos, portanto, alguns frente ao pedido de demissão não receberam o seguro desemprego, o qual também não é liberado diante do rompimento de contratos tão curtos, o que indica que as possibilidades sobre como encaminharam suas vidas são muitas e que a resposta não é tão simples, mas o que é avaliado pelos trabalhadores? O que se considera na decisão de permanecer em um emprego? E na decisão de tentar outras possibilidades?

Interromper um vínculo ou atividade não é um processo tranquilo e algumas dificuldades acredito serem compartilhadas em outros setores, como a dificuldade no 
adoecimento e a falta de respaldo por parte de médicos, o que pode dificultar o acesso a outro trabalho, falta de apoio e respaldo por parte da empresa e da legislação trabalhista, "pressão dos compromissos com a sobrevivência familiar". A movimentação dos trabalhadores na cidade, que perpassam ou não o vínculo com os frigoríficos, exige deles uma avaliação das possibilidades e da forma como irão se colocar em novas relações, a qual se dá frente às diversas pressões e limitações de classe por eles vivenciadas.

Observei na ficha preenchida por $\operatorname{Marta}^{13}$ que em 08/04/2005 o SINE a encaminhou até a empresa frigorífica Copagril pela primeira vez, onde ela foi contratada. Infelizmente não tivemos acesso ao tempo de duração do contrato. Entretanto, 2 anos e 5 meses depois em 26/09/2007 ela procurou a agência sendo novamente encaminhada para uma vaga na mesma empresa e foi contratada. Procurou o SINE mais uma vez em 17/03/2009 o que sabemos em função de sua ficha ser atualizada nesta data, sem nenhum encaminhamento até 29/07/2009 quando, após esta data, obteve dois encaminhamentos em dois meses, e aceitou o último deles (o que ocorreu em 29/09/2009). Contudo, quatro meses depois procurou o SINE novamente e foi encaminhada pela $3^{\circ}$ vez ao frigorífico e foi recontratada, mas um mês depois já constam novos encaminhamentos, e de 01/03/2010 a 27/09/2010 constam 5 encaminhamentos de entrevistas sem nenhum contrato estabelecido.

A desigualdade e exploração presente nestas relações pressionam de forma que as ações destes sujeitos podem não ser suficientes para a conquista de alguma melhoria no modo de vida, por vezes parece ser necessário reavaliar e se recolocar. A ficha preenchida por Marta evidencia que ela estabeleceu relação de trabalho no frigorífico em três momentos, sugerindo que não são ações definitivas e a dificuldade de alguns trabalhadores em se estabelecer em alguma atividade que corresponda àquilo que vêm procurando.

Uma indústria de materiais esportivos da cidade também a contratou duas vezes, sendo a primeira em 29/09/2009 e a segunda em 27/09/2010 que foi a última vaga em que o SINE a encaminhou segundo consta na ficha. Portanto, acredito que a necessidade de retornar às empresas com as quais já havia trabalhado e por algum motivo houve um rompimento não era algo confortável a trabalhadora, mas, também, percebo um modo de lidar com suas dificuldades. Afinal, possivelmente avaliando a relação que teve com a empresa e considerando que era possível retornar mantinha essa possibilidade, ainda que indesejada, pois sempre a abandonava na primeira oportunidade.

\footnotetext{
${ }^{13}$ Os nomes dados são pseudônimos, consideramos prudente manter o sigilo sobre sua identificação.
} 
Sua ficha sugere que seu campo de atuação não se limitou às contratações com registros e, por isso, é difícil mapear as decisões de Marta. Contudo, é possível dizer que conhecia um universo de trabalho que a fazia reagir perante as relações de trabalho estabelecidas e o que elas materializavam em sua vida. Sendo suas práticas compartilhadas com outros trabalhadores da cidade, inclusive, com alguns com quem conversei.

A trajetória de Fatima é marcada por movimentações que não se limitam à cidade de Marechal e nem mesmo a um único tipo de atividade. A trabalhadora elabora a interpretação a seguir ao falar de como considera injusto ter perdido seu emprego em uma creche pública onde era contratada após não passar no concurso, sua narrativa nos permite perceber como tem se colocado nessas disputas e como precisou se dispor a certas mudanças justamente como forma de enfrentar sua condição de trabalhadora:

Fátima: Então assim não adianta você... a pessoa ter um monte de estudo e na hora de fazer não sabe, eu trabalhei em tudo que você imagina. Hoje em dia... eu já trabalhei em tudo, eu já trabalhei em lavagem de carro, eu já trabalhei em cozinha, eu já trabalhei em faxina, eu já trabalhei em casa, eu já trabalhei em roça, não tem o que você chega e pedi pra mim que é difícil o que eu [...] a não ser profissão de homem né? Desde que seja uma profissão de mulher, eu sei fazer. ${ }^{14}$

A trabalhadora fala de profissões diversas as quais já exerceu, procurando indicar que não está apenas disposta a fazer outras atividades, mas que já fez e continua fazendo, lidando com sua condição de trabalhadora, ao passo que está planejando conciliar os trabalhos de cozinheira com o de limpeza de túmulos e de obras. Mudanças nos tipos de trabalho que realiza as quais sugere sua dificuldade em fixar-se em algo que lhe seja recompensador dentro do seu campo de possibilidades, o que por vezes é restringido pelo (re)organizar e (re)planejar seu espaço e modo de viver a cada alteração em suas relações.

Fátima indica maneiras de lidar com as demandas de mão de obra, procurando se favorecer daquilo que percebe enquanto serviços necessários, driblando as limitações das vagas em aberto, mas indica também uma intensificação do trabalho e da exploração com a qual ela está enfrentando. Suas avaliações sobre esse processo e o modo como se vê nas relações de poder exige o reconhecimento de que sua condição de classe e a pressão para submeter-se a certas condições, não limita sua procura por alterá-la, não significa não percebê-las ou desejá-las ou muito menos encerrar suas confrontações. Mesmo que suas ações sejam pressionadas e com resultados limitados, acredito na importância de estudarmos suas

\footnotetext{
${ }^{14}$ FÁTIMA (pseudônimo). Entrevista realizada por Saionara Lagos, no Centro de Referência de Assistência Social (CRAS), no dia 11/06/2014. Marechal Cândido Rondon-PR.
} 
atuações enquanto sujeitos sociais, problematizando a dinâmica do que é vivido, pois isso nos ajuda a entender como trabalhadores como Fátima têm enfrentado e se colocado frente às práticas de exploração por eles vivenciadas, produzindo formas de contestar tal opressão e desigualdades que expões os limites que trazem em sua trajetória (falta de escolarização, com foi o caso na vaga da creche).

O que pretendo indicar é que sua condição de classe não limita sua procura por alterála, e que mesmo suas ações sendo pressionadas e com resultados limitados, a importância de estudarmos suas atuações enquanto sujeitos sociais expõe a dinâmica do que é vivido, ajudanos a entender como eles têm enfrentado e se colocado frente às práticas de exploração, suas ações indicam que rejeitam certas relações e se propõe a arriscar a confrontá-las.

Fátima levanta outro ponto importante de discussão, destaca a importância que tem a sua capacidade para desenvolver as atividades que realiza, mais que o estudo regular, ela indica uma questão similar a outros trabalhadores que compartilham dessa mesma condição para construir legitimidade no que faz. Ela estudou até a quarta série e sabe "fazer de tudo" e tenta me convencer dessa condição, apontando sua capacidade para realizar diversas atividades e isso em sua visão lhe garante uma gama de trabalhos, apesar da falta de escolaridade formal para garantir alguns outros.

Constrói essa argumentação ao falar do quanto considera injusto ter perdido trabalhos para outras pessoas que tivessem formação no ensino regular, o que justifica ter necessitado encontrar outras formas de se destacar na concorrência por vagas de trabalho. Esse é um dos momentos da entrevista em que a relação fica tensa e explícita, e que pode ser percebida à luz do que Portelli (1997) definiu como um "experimento em igualdade", por maior que seja a tentativa de aproximação a relação de poder continua presente e interferindo na forma como construímos o diálogo e aproximação, ela diz que respeita quem tem estudo - afinal ela sabia que eu estava no curso superior - mas, por outro lado, recompõe sua imagem dizendo que a ela o estudo não fez falta, pois "o estudo não vale mais que a experiência"15. Uma forma de se indicar forte na concorrência desleal que lhe fez perder a vaga de trabalho, mas que ainda assim não garante a outros, muitas vezes o saber fazer, que ela reconhece para si.

Sua tentativa de garantir um leque de possibilidades e a maneira como tem se colocado frente suas necessidades de classe não são suficientes para evitar as dificuldades que a vida lhe impõe, como momentos de desemprego, mas evidencia como ela os tem enfrentado.

\footnotetext{
${ }^{15}$ FÁTIMA (pseudônimo). Entrevista realizada por Saionara Lagos, no Centro de Referência de Assistência Social (CRAS), no dia 11/06/2014. Marechal Cândido Rondon-PR.
} 
Muito próximo ao que outros trabalhadores na cidade também procuraram fazer ao se colocarem em anúncios e atividades de trabalho.

Os anúncios de procura por trabalho no jornal "O Presente" são fontes que possibilitaram pensar na forma como alguns trabalhadores estão enfrentando esses momentos, um deles chamou minha atenção:

03/03/2000 - TRABALHO

Moça, boa aparência, 19 anos, procura, como secretária, balconista ou serviços gerais. Possui referências. Tr. $(0 \mathrm{XX} 45) \mathrm{xxx}-\mathrm{Xxxx} \mathrm{c} /$ Tatiane. $^{16}$

Tatiane constrói o anuncio de forma a trazer primeiro suas características físicas, que avaliou enquanto algo que poderia diferenciá-la e que percebe como algo que é levado em consideração ao contratarem para as vagas que sugere em seu anúncio. Ao fim indica que possui referências, essa última indicação se faz presente na grande maioria dos anúncios, supõe-se por ser reconhecida entre os trabalhadores enquanto uma exigência comum feita pelos contratantes e identificada nos anúncios de vagas de trabalho que terminam em grande parte com a mesma exigência "com experiência".

Tatiane organiza suas pretensões de modo a indicar como principal interesse o trabalho como secretária e balconista, mas, sua pequena mensagem anuncia ao fim que aceitaria a condição de serviços gerais. Ceder às urgências de renda e se colocar em vagas que não eram suas expectativas, mas aquelas que reconhecem disponíveis para um conjunto de trabalhadores sem maiores qualificações profissionais indica como as ações e intervenções dos sujeitos no modo como as desiguais possibilidades de empregabilidade se colocam também tem limites, até mesmo nos anúncios construídos pelos próprios trabalhadores.

O modo que formula o anúncio indica como articula sua inserção em um campo que está sendo disputado, além disso expressa como dialoga com as ocupações que vê como possibilidade de inserção. Portanto, sugere quais vagas visualiza como certa demanda comum de trabalhadores, define essas "opções" enquanto pretensão e avaliação do lugar social que ocupa, porém não se restringe a apenas uma opção, dando espaço para diferentes encaminhamentos e modos de tratar tal realidade, deixando claro em que campo de forças apresenta suas aspirações.

A pesquisa no jornal "O Presente" chamou a atenção para outro encaminhamento dessas relações, que também foram percebidos nas entrevistas, indicado pelo empresariado

\footnotetext{
${ }^{16}$ CLASSIFICADOS. Jornal O Presente, Marechal Cândido Rondon, 03 de março de 2000, p. 45.
} 
como rotatividade dos trabalhadores, a qual é interpretada no jornal como falta de comprometimento e interesse dos mesmos, expressando o incômodo que suas ações têm provocado no empresariado da cidade frente as relações de trabalho.

Em 18 de Janeiro de 2013 o jornal noticia o início da construção do SENAC ${ }^{17}$, a qual ganha destaque na capa do periódico, destaca o ganho com essa instituição na promoção de cursos e profissionalização de trabalhadores. O que chama a atenção é a preocupação expressa no texto em apontar certa avaliação: jovens trabalhadores não permanecem nas vagas de trabalho disponibilizadas.

O editorial indica que há uma "falta de comprometimento", sugerindo também um problema geracional; "a nova geração de trabalhadores não busca se firmar em uma mesma empresa" e anunciam o descaso desses novos trabalhadores com as 'normas de trabalho', apontando faltas ao trabalho, interesse em vínculo apenas até garantir seguro-desemprego etc. $^{18}$

Aquilo que nas entrevistas aparece enquanto sentimento de exploração exacerbada, na medida em que se colocam a realizar determinada atividade para responder suas necessidades materiais (ainda que continuem a procurar novas ocupações que possibilitem alguma alteração em sua condição de vida), é, contraditoriamente, visto pelo periódico como "falta de comprometimento" com a classe patronal.

Essa interpretação publicada no periódico é direcionada a culpabilizar os trabalhadores pelo desenrolar dessas situações, retirando da classe patronal qualquer responsabilidade pelas relações de trabalho e o que levam a abandoná-las sucessivamente. Mas, na medida em que os empregadores têm se colocado na disputa pela interpretação e pela visibilidade das relações classistas, das ações e modos como esses trabalhadores estão se relacionando com o trabalho, é um sintoma de que suas ações/atuações vêm incomodando e sendo pauta popular.

É relevante considerar que a entrevista com Paulo foi produzida no ano de 2013, mesmo ano da produção do editorial acima discutido, sabe-se que ambas são construções pautadas em interesses e que esses são divergentes, mas problematizar como em um mesmo momento histórico as preocupações são tão distintas é o nosso papel.

Longe de esgotar as possibilidades de discussão, minha intenção nessa construção inicial foi levantar pontos que são mais inquietantes para mim ao lidar com esse conjunto de fontes. Procurei problematizar a movimentação dos sujeitos em suas relações com o trabalho

\footnotetext{
${ }^{17}$ EDITORIAL. Ganha o Comércio. Jornal O Presente, Marechal Cândido Rondon, 04 de março de 2013.

${ }^{18}$ Ibidem.
} 
possibilitando um entendimento das tramas da cidade e do processo social que está se desenvolvendo.

Acredito que os sujeitos apresentados trazem trajetórias capazes de expressar conflitos de classe presentes no cotidiano desses trabalhadores. Esse é o caminho de um trabalho de pesquisa que está em andamento, e que a cada passo dado lida com novas perguntas que vem surgindo sobre esse processo.

\section{Referências:}

PORTELLI, Alessandro. Forma e significado na História Oral: A pesquisa como um experimento em igualdade. Projeto História, São Paulo, n.14, p. 7-23, fev. 1997.

História Oral e Poder. Mnemosine, Rio de Janeiro, v.6, n. 2, p. 2-13, 2010.

SANTOS, Carlos Meneses de Sousa. Trabalhadores em Movimento: Horizontes abertos em Marechal Cândido Rondon-PR: Segunda metade do século XX e início do XXI. Jundiaí, Paco Editorial: 2016.

THOMPSON, E. P. Exploração. In.: A formação da classe operária inglesa. A maldição de Adão. 2. ed. Rio de Janeiro: Paz e Terra, 1988. p. 11-38.

Folclore, Antropologia e História Social. In: NEGRO, Antônio L.; SILVA, Sérgio (Orgs.). As peculiaridades dos ingleses e outros artigos. Campinas: Ed. da Unicamp, 2001, p.227-267.

VARUSSA, R. J (Org.). Frigoríficos: abatendo animais, adoecendo trabalhadores. In: $E u$ trabalhava com dor: trabalho e adoecimento nos frigoríficos. Jundiaí: Paco Editorial, 2016, p.33-42.

Trabalhadores e frigoríficos na Justiça do Trabalho: Oeste do Paraná, décadas de 1990 e 2000. In.: GOMES, Ângela C.; SILVA, Fernando T. (Orgs.). A Justiça do Trabalho e sua história: os direitos dos trabalhadores no Brasil. Campinas: Ed. Unicamp, 2013. 